\title{
RESPONSABILIDADE CIVIL SOBRE A POLUIÇÃO SONORA PROVOCADA PELO TRANSPORTE PÚBLICO NA REGIÃO METROPOLITANA DE SÃO PAULO
}

\author{
Renato Ferreira de Souza* \\ Ms Claudete de Souza**
}

\section{RESUMO}

O presente estudo tem o objetivo de demonstrar e informar sobre a responsabilidade civil, por parte do poder público, sobre os danos causados à saúde da população, decorrentes da poluição sonora no transporte público que circula na Região Metropolitana de São Paulo e seus arredores. Abrange, ainda, a análise das legislações vigentes nos municípios de São Paulo, Santo André e São Bernardo do Campo, a respeito do controle e fiscalização da emissão de ruídos, estabelecendo limites que devem ser cumpridos por todos. Serão demonstrados os problemas em que a mera exposição aos ruídos pode causar à população, de acordo com a recomendação da Organização Mundial da Saúde, além da verificação do papel pertinente ao Ministério Público na defesa do meio ambiente. Existem inúmeras leis que dispõem sobre a poluição sonora, notando-se, no desenvolver desta pesquisa, que falta uma legislação unificada sobre o tema abordado, resultando, atualmente, em uma confusão e grande dificuldade em se discutir o assunto, já que a regulamentação a respeito dos ruídos é variada e diferente em cada município brasileiro.

Palavras-chave: Poluição sonora. Meio ambiente. Responsabilidade civil. Ruídos. Transporte público. Região metropolitana. Danos à saúde.

\section{LEGAL LIABILITY ABOUT NOISE POLLUTION CAUSED BY PUBLIC TRANSPORT IN SÃO PAULO METROPOLITAN REGION}

\section{ABSTRACT}

This work aims to demonstrate and inform about the civil liability, by the Government, about the damage caused to the health of the population, resulting from noise pollution in public transport that circulates in the metropolitan region of São Paulo and its surroundings. It also covers the analysis of the laws in force in the municipalities of São Paulo, Santo André and São Bernardo do Campo, regarding the control and supervision of noise emission, establishing limits that must be met by all. It will be demonstrated the problems in which

* Bacharel em Direito pela Universidade Metodista de São Paulo.

* 'Doutoranda em Educação na Universidade Metodista de São Paulo. Mestre em Direito pela Universidade Metropolitana de Santos. Professora Civilista, na Universidade Metodista de São Paulo. Advogada. 
the mere exposure to noise can cause the population, according to the recommendation of the World Health Organization, besides the verification of the pertinent role to the Public Prosecution Service in the defense of the environment. There are numerous laws that provide for noise pollution, noting, in the development of this research, that there is a lack of unified legislation on the subject addressed, currently resulting in confusion and great difficulty in discussing the subject, since the regulation to Noise respect is varied and different in each Brazilian city.

Keywords: Noise pollution. Environment. Civil responsability. Noises Public transportation. Metropolitan region. Harm to health.

\section{INTRODUÇÃO}

Nosso estudo tem por finalidade indagar e informar o leitor sobre a viabilidade da responsabilização civil do Estado em decorrência da exposição de pessoas em ambientes próximos aos locais onde trafega o transporte público, especificamente o transporte sobre trilhos (trens e metrô) e ônibus, que proporcionam grandes concentrações de poluição sonora, apresentando, por outro lado, sugestões para a solução do problema.

Utilizaremos como base para esta pesquisa, os principais meios de combate ou prevenção à poluição sonora, compreendidos por três municípios da Região Metropolitana de São Paulo, sendo a capital (São Paulo), Santo André e São Bernardo do Campo, restringindo apenas a estas três cidades, embora a Região Metropolitana de São Paulo abranja muitas outras, no sentido de focar mais restritamente nossa pesquisa.

Estas três cidades possuem um alto índice populacional, sendo São Paulo a cidade mais populosa do Brasil (IBGE, 2019). Quanto a Santo André e São Bernardo do Campo, estas possuem destaque, por serem, historicamente, cidades industriais, e consequentemente, caracterizando-se como uma região agitada e barulhenta.

É sabido que o avanço acelerado do crescimento da cidade de São Paulo, apresenta efeitos dos mais nocivos para seus habitantes, qual seja, a poluição, em suas várias espécies, causada pelos meios de transporte coletivo, o que vem conquistando, cada vez mais intensamente, espaço em nosso cotidiano. O senso comum também não ignora, apesar de haver reiteradas comprovações científicas, sobre os sérios danos à saúde por esse fato provocado.

Principalmente em grandes cidades, caso de São Paulo, onde a vida é agitada e a população residente cresce continuamente, a poluição sonora, em grande parte provocada pelos meios públicos de locomoção, tem despertado grandes frustrações à população.

Após um dia agitado e estressante procura-se somente o sossego, o descanso e a paz necessários a recompor-se para o dia seguinte, oportunidade para um novo e árduo trabalho.

O problema da poluição sonora se manifesta, sobretudo, para a população residente próxima aos locais onde mais trafega o transporte público metropolitano sobre trilhos (trens e metrô), além dos ônibus e seus respectivos terminais. 
O ruído produzido por esse tipo de transporte, pode ser prejudicial, ocasionando irritabilidade aos moradores próximos.

Tal perturbação poderá resultar em graves riscos à saúde, caso em que, devido ao alto índice de reclamações, levou o poder público a providenciar medidas necessárias a fim de combater o problema, tentando garantir, assim, o direito à paz, a dignidade, ao descanso e ao sossego.

Porém, mais do que os estudos indicam, a realidade nos mostra que essa adversidade ainda persiste.

São inúmeros os danos à saúde ocasionados em decorrência da exposição da pessoa em um ambiente com grande concentração de poluição sonora, refletidos tanto no físico quanto no emocional. Segundo matéria transmitida no Bom Dia Brasil (transmissão ao vivo na Rede Globo, em 24 de abril de $2019^{1}$, as doenças decorrentes da poluição vão da depressão até problemas cardiovasculares.

Além das inúmeras dificuldades que poderão impactar negativamente a saúde, ao analisar a situação percebe-se que o direito ao sossego, decorrente do respeito ao princípio da dignidade da pessoa humana também é afetado, sendo esse direito garantido tanto pela Constituição Federal de 1988, quanto pelas leis infraconstitucionais.

A partir desse princípio, será possível observar o descumprimento ao direito ao sossego, além de outros direitos dispostos nas diversas leis, como normas federais, estaduais, municipais e convenções internacionais.

É nosso entendimento que compete ao poder público estabelecer parâmetros que respeitem, fiscalizem e controlem o volume de ruídos sonoros, já que as leis determinam os limites máximos de ruídos permitidos. Portanto, seu eventual descumprimento poderá acarretar a aplicação da responsabilização civil ao Estado, exigindo dos órgãos públicos indenização correspondente ao bem jurídico lesionado.

Portanto, quando o próprio Estado, exercendo a sua função de prestador dos serviços necessários à locomoção de uma grande população, prejudicar ou causar dano ao cidadão, como agente poluente de sons, deverá, o mesmo, repará-los. A responsabilidade civil imputada ao Estado, como pacificado, é da modalidade objetiva, sendo desnecessária a apuração de culpa ou dolo na causação do prejuízo.

Ainda, abordaremos a atuação do Ministério Público no que diz respeito à tutela do direito ambiental, incluindo suas funções e meios investigatórios para a apuração dos danos ao meio ambiente.

\section{POLUIÇÃO SONORA E OS DANOS À SAÚDE}

O mundo contemporâneo possibilita ao ser humano uma série de facilidades, dentre estas, a agilidade de sua locomoção, principalmente nos grandes centros urbanos. Por outro lado, ainda não se descobriu a tecnologia ideal que possibilite produzir meios de transporte sem qualquer emissão de ruídos. Portanto, há um nocivo efeito colateral provocado pelos transportes oferecidos à população, os quais possibilitam suprir a necessidade sempre crescente da mobilidade rápida.

1 Disponível em https://g1.globo.com/bom-dia-brasil/) 
A poluição sonora está diretamente ligada ao conceito físico de som e ruído, tratando- se o som, segundo Fiorillo (2013, p. 333) como "qualquer variação de pressão (no ar, na água...) que o ouvido humano possa captar, e quanto ao ruído, apesar de ser uma espécie de som, é desagradável, perturbador e indesejável ao ouvido humano".

Vale lembrar que muitos ruídos são praticamente imperceptíveis, mas, mesmo assim, não deixam de ser prejudiciais à saúde humana.

Arquivado desde janeiro de 2019, o projeto de Lei $\mathrm{N}^{\circ} 1.073 / 15$, define a poluição sonora como "produção de sons, ruídos ou vibração em desacordo com a prescrição legal ou regulamentar", e tem por objetivo, enquadrar ao artigo 54 da lei de crimes ambientais.

O Senado Federal já demonstrava preocupação com a poluição sonora, quando, em junho 2012, publicou um outro artigo em seu jornal, por intermédio do jornalista Márcio Maturana, criticando a Conferência das Nações Unidas acerca do Desenvolvimento Sustentável (RIO+20), na qual não houve, sequer, menção sobre a poluição sonora.

No artigo, além de sua crítica, o Senado Federal admitiu a falta de uma legislação nacional sobre a poluição sonora:

Criou-se uma ideia errada de que o Brasil tem uma "Lei do Silêncio"
que proíbe abusar de ruídos antes das 8 h e depois da $22 \mathrm{~h}$. Na verda-
de, não existe essa lei nacional e não se pode fazer barulho em horário
nenhum. O que existe de fato é um conjunto de normas desde a Cons-
tituição Federal (Artigo 225) até Convenções de Condomínio, além de
políticas urbanas envolvendo órgãos federais, estaduais e municipais.
Tudo varia de estado para estado e de município para município. (MA-
TURANA. 2012, p. 01)

No ano de 2018, o Senado Federal, por intermédio do jornalista Ricardo Westin, publicou um artigo sobre os riscos da poluição sonora e as possíveis reações do corpo humano ao estar em ambientes barulhentos:

O barulho, mesmo não sendo escandaloso, é interpretado pelo organismo como prenúncio de perigo. Para que a pessoa tenha energia para se defender, suas reservas de açúcar e gordura são liberadas. Esgotado o estoque de energia, surgem cansaço, irritabilidade, estresse, ansiedade, insônia, falha de memória, falta de concentração, gripe e até doenças cardíacas, respiratórias, digestivas e mentais. (Agência Senado, 2018).

Ainda em 2018, a Organização Mundial da Saúde publicou um relatório sobre o problema da poluição sonora na Europa, estabelecendo parâmetros dos limites máximos aos quais uma pessoa poderá ficar exposta sem que lhe cause danos à sua saúde auditiva.

O relatório estabelece que para o transporte sobre trilhos (em inglês: Railway), os níveis de ruídos devem estar abaixo dos 54 decibéis, durante o dia, e 44 decibéis, durante a noite, para que não surjam problemas relacionados à saúde das pessoas: 
Para exposição média ao ruído, o GDG recomenda fortemente reduzir os níveis de ruído produzidos pelo tráfego ferroviário abaixo de $54 \mathrm{~dB}$ $\mathrm{L}_{\text {den' }}$ pois o ruído ferroviário acima desse nível está associado a efeitos adversos à saúde. Para exposição ao ruído noturno, o GDG recomenda enfaticamente a redução dos níveis de ruído produzidos pelo tráfego ferroviário durante o período noturno abaixo de $44 \mathrm{~dB} \mathrm{~L}_{\text {night' }}$ pois o ruído ferroviário noturno acima desse nível está associado a efeitos adversos no sono. (ORGANIZAÇÃO MUNIDAL DA SAÚDE. Diretrizes de Ruído Ambiental para a Região Europeia, 2018, p. 49. Tradução nossa)

Logo, o Grupo de Desenvolvimento de Diretrizes (Guideline Development Group - GDG) informa que a exposição ao ruído, durante o período noturno, pode ocasionar problemas relacionados ao sono.

Já no período diurno, de acordo com a Organização Mundial da Saúde (2018), a exposição aos ruídos sonoros pode provocar diversos distúrbios, como doenças cardiovasculares, aborrecimentos, comprometimento cognitivo, deficiência auditiva e zumbidos, efeitos negativos na qualidade de vida, bem-estar e saúde mental, em resultados metabólicos e até disfunções durante o nascimento de uma pessoa.

Como medida preventiva, a OMS recomenda o uso de políticas que visem a redução dos ruídos em trens e metrôs, ou seja, uma eventual modernização do equipamento, entendendo que não há a possibilidade de recomendar alguma alteração/intervenção no sistema, uma vez que a linha férrea é fixa ao solo:

Para reduzir os efeitos na saúde, o GDG recomenda enfaticamente que os formuladores de políticas implementem medidas adequadas para reduzir a exposição ao ruído das ferrovias na população exposta a níveis acima dos valores das diretrizes para exposição ao ruído médio e noturno. No entanto, não há evidências suficientes para recomendar um tipo de intervenção em detrimento de outro. (ORGANIZAÇÃO MUNDIAL DA SAÚDE. Diretrizes de Ruído Ambiental para a Região Europeia, 2018, p. 49. Tradução nossa)

Por outro lado, quanto ao tráfego, no qual se inclui o transporte público coletivo, o relatório recomenda que durante o dia, os níveis de ruídos estejam abaixo dos 53 decibéis, e durante a noite, abaixo dos 45 decibéis:

Para exposição média ao ruído, o GDG recomenda fortemente reduzir os níveis de ruído produzidos pelo tráfego rodoviário abaixo de $53 \mathrm{~dB}$ $\mathrm{L}_{\text {den' }}$ pois o ruído do tráfego rodoviário acima desse nível está associado a efeitos adversos à saúde. Para a exposição ao ruído noturno, o GDG recomenda enfaticamente a redução dos níveis de ruído produzidos pelo tráfego durante o período noturno abaixo de $45 \mathrm{~dB}_{\mathrm{n}_{\text {night' }}}$ pois o ruído do tráfego acima deste nível está associado a efeitos adversos no sono. (ORGANIZAÇÃO MUNDIAL DA SAÚDE. Diretrizes de Ruído Ambiental para a Região Europeia, 2018, p. 30. Tradução nossa) 
Quanto à prevenção, a recomendação do transporte sobre trilhos aplica-se ao tráfego rodoviário, optando mais uma vez pela criação de políticas que visem a redução das emissões de ruídos, porém, reconhecendo a possibilidade da adoção de intervenções, como a mudança de rotas dos veículos automotores:

\footnotetext{
Para reduzir os efeitos na saúde, o GDG recomenda enfaticamente que os formuladores de políticas implementem medidas adequadas para reduzir a exposição ao ruído do tráfego rodoviário na população exposta a níveis acima dos valores das diretrizes para exposição ao ruído médio e noturno. Para intervenções específicas, o GDG recomenda reduzir o ruído tanto na fonte quanto na rota entre a fonte e a população afetada pelas mudanças na infraestrutura. (ORGANIZAÇÃO MUNIDAL DA SAÚDE. Diretrizes de Ruído Ambiental para a Região Europeia, 2018, p. 30. Tradução nossa)
}

A OMS afirma que 1 (um) a cada 5 (cinco) europeus estão regularmente expostos aos altos índices de ruídos durante a noite, podendo causar danos significativos à saúde dos europeus.

Cerca de $40 \%$ da população europeia estão expostos aos ruídos sonoros decorrentes do trânsito, excedendo aos 55 decibéis (o limite segundo a recomendação é de $53 \mathrm{~dB}$ ), 20\% estão expostas a níveis acima de 65 decibéis durante o dia, e 30\% da população estão expostos a níveis acima de 55 decibéis durante a noite (limite máximo recomendado $45 \mathrm{~dB}$ ).

A Organização Mundial da Saúde ainda informa que os grupos mais afetados pela poluição sonora são as crianças, doentes crônicos e idosos, além dos trabalhadores. Como efeitos na saúde das crianças foram detectados prejuízos na performance cognitiva, pressão sanguínea e hormonais.

Portanto, diante das inúmeras informações expostas, inegável que a poluição sonora é prejudicial à saúde e, apesar de ser pouco abordada por pesquisas e pelo poder público, percebemos que existe uma grande preocupação a respeito, por parte da Organização Mundial da Saúde, além de algumas instituições brasileiras, como o Senado Federal, por exemplo.

\section{A ESSENCIALIDADE DO TRANSPORTE PÚBLICO METROPOLITA- NO E PREVISÃO LEGAL DA POLUIÇÃO SONORA}

Atualmente (2019) a Região Metropolitana de São Paulo é o maior centro urbano do Brasil, da América Latina e de todo o Hemisfério Sul do planeta e, segundo a Empresa Paulista de Planejamento Metropolitano (sigla EMPLASA, atualmente extinta), é o maior polo de riqueza nacional.

A Região Metropolitana de São Paulo (RMSP, de acordo com a EMPLASA, foi instituída em 08 de junho de 1973, pela Lei Complementar Federal No 14, juntamente com outras sete regiões metropolitanas, sendo reorganizada pela Lei Complementar $\mathrm{N}^{\mathrm{o}} 1.139 / 11$.

Inicialmente contando com 37 municípios para a RMSP, a Lei Complementar prevê serviços de interesse comum metropolitano, como o uso do solo metropo- 
litano, transportes e sistemas viários, com destaque para o controle da poluição ambiental, in verbis:

Art. $5^{\circ}$ - Reputam-se de interesse metropolitano os seguintes serviços comuns aos Municípios que integram a região:

- aproveitamento dos recursos hídricos e controle da poluição ambiental, na forma que dispuser a lei federal. (BRASIL. Planalto, Lei Complementar 14/1973).

De acordo com o Estatuto da Metrópole (Lei No 13.089/2015), uma Região Metropolitana somente pode ser instituída mediante Lei Complementar Estadual:

Art. $2^{\circ}$ Para os efeitos desta Lei, consideram-se:

- região metropolitana: unidade regional instituída pelos Estados, mediante lei complementar, constituída por agrupamento de Municípios limítrofes para integrar a organização, o planejamento e a execução de funções públicas de interesse comum; (BRASIL. Planalto, Lei 13.089/2015)

Deste modo, considera-se que desde a década de 70, a RMSP demonstra preocupação com a poluição do meio ambiente.

Conforme o mencionado, além da preocupação com o meio ambiente, o legislador deu destaque ao sistema geral de transporte, no qual se inclui o transporte público. É notável tal discussão apresentada pela Lei Complementar, dado ao fato anteriormente citado, de que a Região Metropolitana de São Paulo é a região de maior aglomeração urbana do país.

Diante desta linha de raciocínio, é evidente a necessidade de transporte público satisfatório para a alta demanda populacional.

A Lei No 12.587 de 03 de janeiro de 2012, dispõe sobre a Política Nacional da Mobilidade Urbana; de acordo com o seu artigo $1^{\circ}$, tem como finalidade, a melhoria da acessibilidade e mobilidade das pessoas:

Art. $1^{\circ}$ A Política Nacional de Mobilidade Urbana é instrumento da política de desenvolvimento urbano de que tratam o inciso XX do art. 21 e o art. 182 da Constituição Federal, objetivando a integração entre os diferentes modos de transporte e a melhoria da acessibilidade e mobilidade das pessoas e cargas no território do Município. (BRASIL. Planalto, Lei $12.587 / 2012)$.

Dessa maneira, observa-se que o artigo anterior nos remete à Constituição Federal, tanto que, em seu artigo 182, determina que a regulamentação da política de desenvolvimento urbano fica a cargo do poder municipal, por meio do plano diretor.

O plano diretor, por sua vez, é regulamentado pelo Estatuto da Cidade (Lei No 10.257/01), sendo interessante observar que, em seu artigo 41, obriga a determinados municípios a criação de um plano diretor, e consequentemente, a obrigação da criação de um plano de transporte urbano integrado para os municípios que 
possuem mais de quinhentos mil Habitantes. A Região Metropolitana de São Paulo conta atualmente com aproximadamente 21 (vinte e um) milhões de habitantes (2015), segundo a informação disponibilizada pelo Plano de Desenvolvimento Urbano Integrado.

Art. 41. O plano diretor é obrigatório para cidades:

- integrantes de regiões metropolitanas e aglomerações urbanas;

$\S 2^{\circ}$ No caso de cidades com mais de quinhentos mil habitantes, deverá ser elaborado um plano de transporte urbano integrado, compatível com o plano diretor ou nele inserido. (BRASIL. Planalto, Lei 10.257/2001)

Desta linha, para todos os municípios integrantes da Região Metropolitana de São Paulo deve haver um plano diretor e os municípios com mais de quinhentos mil habitantes, no qual se inclui os municípios de São Paulo, Santo André e São Bernardo do Campo, que devem possuir um plano de transporte urbano, nele inserido o transporte público coletivo.

Diante dessa conhecida premência do transporte público, Gonzaga Patriota escreve em seu artigo, publicado em 2013:

De fundamental importância nas cidades é o transporte público coletivo no qual várias pessoas são transportadas juntas em um mesmo veículo. Nas cidades grandes, o transporte coletivo urbano também tem a função de proporcionar uma alternativa de transporte em substituição ao automóvel, visando à melhoria da qualidade de vida da comunidade mediante a redução da poluição ambiental [...].

O transporte público é, assim, imprescindível para a vitalidade econômica, a justiça social, a qualidade de vida e a eficiência das cidades modernas. (PATRIOTA. 2013. p. 01)

Conforme o exposto, e observadas as legislações, é incontestável a necessidade do transporte público coletivo na Região Metropolitana de São Paulo, pois, devido à alta concentração de população na região, precisou-se criar sistemas de mobilidade, como exige o Estatuto da Cidade, e além disso, devemos observar que o uso do transporte público é diretamente relacionado ao direito à liberdade de locomoção (art. $\left.5^{\circ}, \mathrm{XV}\right)$, garantido como direito fundamental pela Constituição Federal.

O município de São Paulo, conforme os dados disponibilizados pelo Instituto Brasileiro de Geografia e Estatísticas (IBGE), pela estimativa populacional para o ano de 2019, é o município mais populoso do Brasil.

A Lei Municipal No 16.402, aprovada em de 22 de março de 2016, dispõe sobre o uso do solo em todo o território da municipalidade. Desta forma, o legislador incluiu uma seção única na lei, na qual dispõe sobre os parâmetros de incomodidade.

Em seu artigo 146, proibiu-se a produção de todo e quaisquer ruídos acima daquele por ela permitido, que serão fiscalizados, de acordo com o $\$ 1^{\circ}$, por agentes competentes.

A lei ainda traz uma tabela, em seu anexo de quadro $4 \mathrm{~B}$, que demonstra os limites de ruídos permitidos nas grandes áreas urbanas, observando os horários e o tipo de zona, como segue: 
Figura 1: Quadro 4B - Parâmetros de Incomodidade por zona.

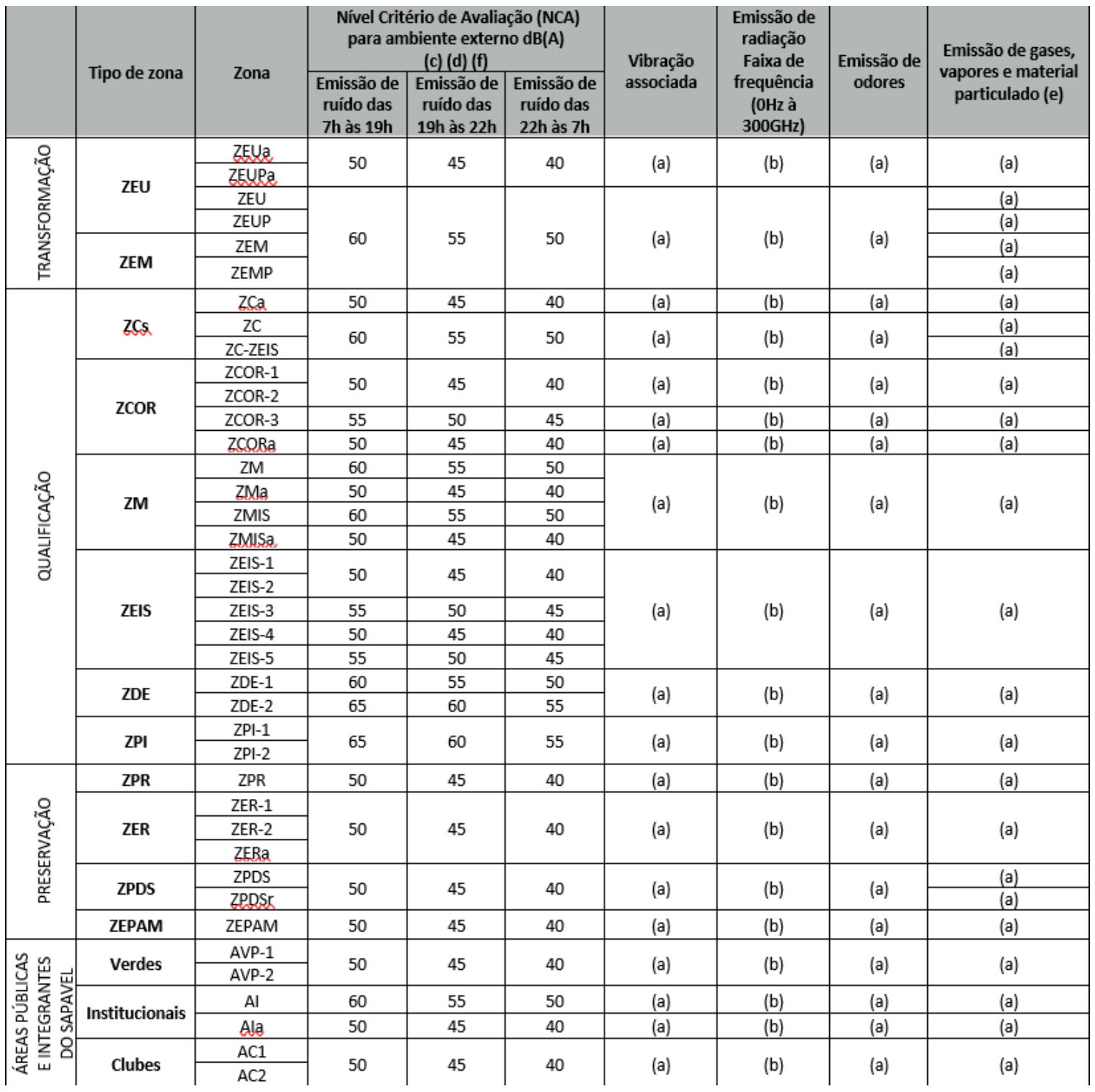

Fonte: Prefeitura de São Paulo (2019)

Fazendo parte da Região Metropolitana de São Paulo e da Região do Grande $\mathrm{ABC}$, o município de Santo André tem vivenciado um grande aumento populacional nos últimos anos e, consequentemente, por localizar-se próxima da capital do estado, compartilha problemas semelhantes quanto ao excesso de ruídos, especificamente se tratando daqueles provocados pelo transporte público.

Em 21 de julho de 2014, foi aprovada no município a Lei № 9.608, dispondo também sobre poluição sonora, porém, somente quanto aos veículos automotores na cidade. Trata-se de um avanço no reconhecimento do município, acerca dos perigos consequentes dos altos níveis de ruídos sonoros produzidos por veículos automotores. 
Apesar do artigo $1^{\circ}$ esclarecer que a limitação dos ruídos sonoros é somente proveniente de aparelhos de som, o artigo $4^{\circ}$ determina a proibição da emissão de ruídos de quaisquer veículos automotores:

Art. $4^{\circ}$ Fica proibida a emissão de sons e ruídos em veículos de quaisquer espécies acima dos níveis máximos em decibéis de acordo com o período, conforme disposto na tabela prevista no art. $3^{\circ}$ da presente lei. (SANTO ANDRÉ. Câmara Municipal, Lei Municipal 9.608/2014)

Assim, observada a proibição, o artigo $3^{\circ}$ traz a seguinte tabela, na figura 2, estabelecendo os padrões de incomodidade admissíveis:

Figura 2: Padrões de Incomodidades admissíveis para a Macrozona Urbana.

\begin{tabular}{|c|c|c|}
\hline \multicolumn{2}{|c|}{ Padrões de Incomodidades admissíveis para a Macrozona Urbana: } \\
\hline \multirow{2}{*}{ Nível de Incomodidade } & Diurno: & Noturno: \\
& das $7 \mathrm{~h}$ às $22 \mathrm{~h}$ & das $22 \mathrm{~h}$ às $7 \mathrm{~h}$ \\
\hline Não Incômodo & $55 \mathrm{~dB}(\mathrm{~A})$ & $50 \mathrm{~dB}(\mathrm{~A})$ \\
\hline Incômodo I & $60 \mathrm{~dB}(\mathrm{~A})$ & $55 \mathrm{~dB}(\mathrm{~A})$ \\
\hline Incômodo II e II & $65 \mathrm{~dB}(\mathrm{~A})$ & $60 \mathrm{~dB}(\mathrm{~A})$ \\
\hline Incômodo IV & $70 \mathrm{~dB}(\mathrm{~A})$ & \\
\hline
\end{tabular}

Fonte: Santo André. SISCAM (2019)

Entretanto, cada região desse município, assim como os demais que compõem a Grande São Paulo, possui um nível de incomodidade diferente. É importante que esses padrões sejam observados, pois em uma região o nível de ruído pode ser mais alto do que na outra, devido a suas próprias características.

O município de São Bernardo do Campo, assim como o de Santo André, está em uma região de grande concentração demográfica, e por isso compartilha problemas comuns relacionados à poluição sonora.

Deste modo, em 19 de dezembro de 2013, foi aprovada pela Câmara Municipal de São Bernardo do Campo, a Lei No 6.323, que dispõe sobre os ruídos sonoros provenientes de veículos automotores.

De acordo com o $\operatorname{artigo} 1^{\circ}$ da Lei, é vedada a perturbação do sossego e bem-estar no território de São Bernardo do Campo acima dos limites estabelecidos, incluindo também, os veículos automotores:

Art. $1^{0}$ É vedado perturbar o sossego e o bem-estar públicos com ruídos, vibrações, sons excessivos ou incômodos de qualquer natureza, produzidos sob qualquer forma ou que contrariem os níveis máximos fixados nesta Lei, provenientes de equipamentos móveis, aparelhos de som ou veículos automotores. (SÃO BERNARDO DO CAMPO. Câmara Municipal, Lei Municipal 6.323/2013) 
Ao mesmo tempo, diferentemente de Santo André e São Paulo, a Lei Municipal de São Bernardo do Campo No 6.323/13, que trata da poluição sonora, encontra-se estabelecida de uma forma mais unificada, ou seja, a própria legislação traz conceitos, limites, proibições e competência, o que não ocorre nos demais municípios já abordados.

Diferentemente dos outros municípios tratados, o legislador de São Bernardo do Campo, decidiu classificar os níveis de ruídos, caracterizando ruídos em sua forma leve, até na forma gravíssima, conforme a tabela na figura 3. A classificação deve ser observada no momento da aplicação das penalidades:

Figura 3: Níveis de ruídos excedentes ao estabelecido.

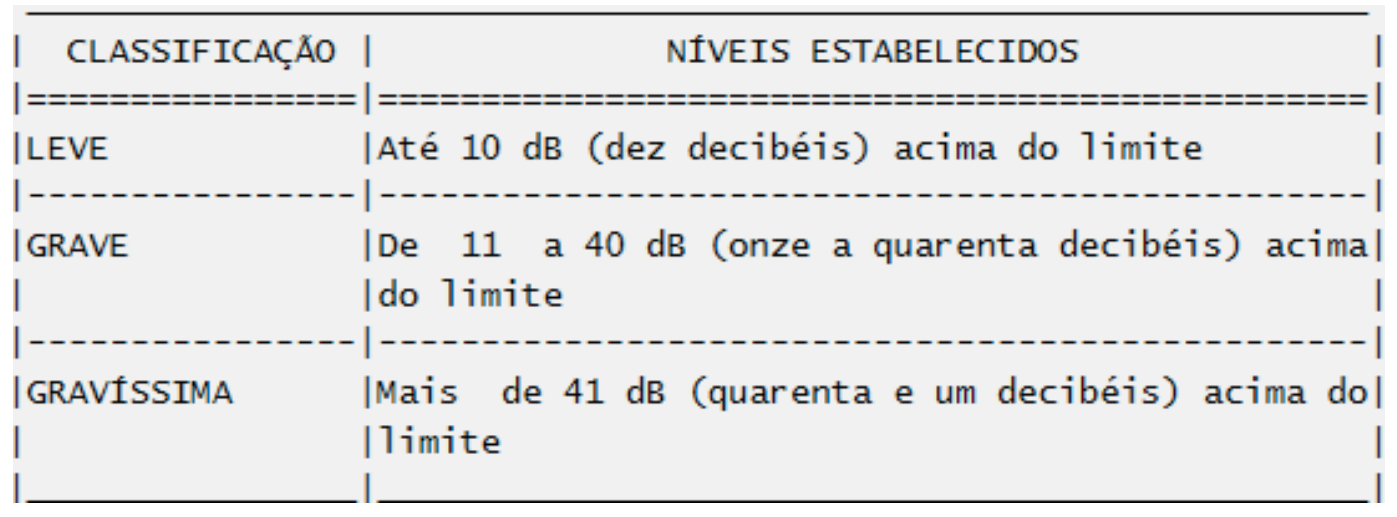

Fonte: São Bernardo do Campo. Leis Municipais (2019)

Ainda, além das formas do nível de ruído, o município leva em consideração a espécie da área, estabelecendo os padrões máximos de incomodidade, de acordo com as áreas residenciais, industriais ou mistas e, também, relacionando o período do dia, sendo diurno ou noturno, conforme a tabela contida na figura 4:

Figura 4: Níveis de ruídos permitidos.

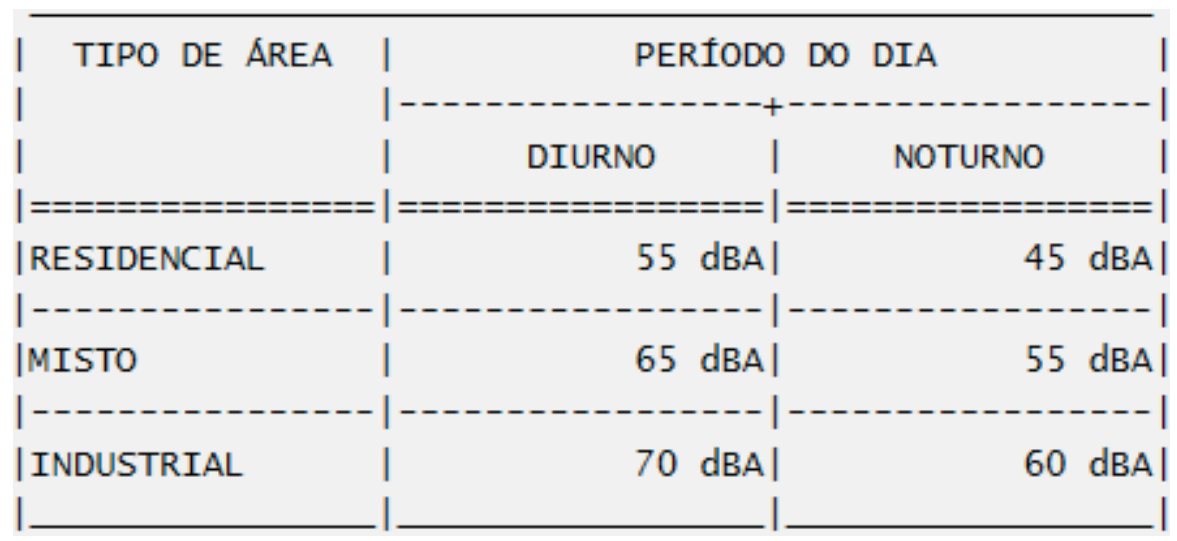

Fonte: São Bernardo do Campo. Leis Municipais (2019) 
Cabe ressaltar que o artigo 15 da Lei 6.323/2013, ainda prevê as penalidades, como multa e sanção (apreensão do veículo), mas destaca-se no texto, quanto às cominações civis, ou seja, o próprio artigo admite o cabimento de eventuais danos na esfera civil, decorrentes da poluição sonora:

\begin{abstract}
Art. 15 Aos infratores dos dispositivos desta Lei serão aplicadas as seguintes penalidades, sem prejuízos das cominações cíveis e penais cabíveis: [...]. (SÃO BERNARDO DO CAMPO. Câmara Municipal, Lei Municipal 6.323/2013)
\end{abstract}

Portanto, fica evidente o cabimento da responsabilidade civil pela poluição sonora, decorrente de veículos utilizados para o transporte, uma vez que a lei refere-se a todas as espécies de veículos automotores e, assim, inclui-se os utilizados para o transporte público, uma vez que a própria lei não dispõe de exceção para este tipo de serviço.

\title{
A RESPONSABILIDADE CIVIL DO ESTADO E DO MINISTÉRIO PÚ- BLICO NA DEFESA DO MEIO AMBIENTE
}

Com relação ao instituto da responsabilidade civil, temos que considerar que a responsabilidade decorre primeiramente "de uma conduta violadora de um dever jurídico [...]" (GONÇALVES. 2018. p. 31), ou seja, gera-se responsabilidade a partir do momento em que descumprimos determinada obrigação, seja imposta pela própria Lei, ou até mesmo, em nosso dia-a-dia.

Segundo Gonçalves (2018), o ato jurídico gera um fato jurídico, podendo ser lícito ou ilícito. Sendo ilícito o ato, surge com ele o dever de indenizar e/ou ressarcir o prejuízo.

Desta maneira, passaremos a estudar as espécies de responsabilidade civil, em sua modalidade subjetiva e objetiva.

No atual Código Civil de 2002, é previsto em seu artigo 927 e parágrafo único, a responsabilidade por causar dano ao outro e a sua obrigação em repará-lo.

Art. 927. Aquele que, por ato ilícito (arts. 186 e 187), causar dano a outrem, fica obrigado a repará-lo. (responsabilidade subjetiva)

Parágrafo único. Haverá obrigação de reparar o dano, independentemente de culpa, nos casos especificados em lei, ou quando a atividade normalmente desenvolvida pelo autor do dano implicar, por sua natureza, risco para os direitos de outrem. (responsabilidade objetiva - pessoas jurídicas). (BRASIL. Planalto, Lei 10.406/2002)

Na responsabilidade subjetiva apura-se a culpa do agente que praticou o ato lesivo, sendo necessário, para a sua caracterização com consequente indenização, que a atitude esteja imbuída de negligência, imprudência ou imperícia. Portanto, ausente uma destas três modalidades, não há que se falar em culpa e, consequentemente, não se configura como responsabilidade subjetiva. 
De outro lado, na responsabilidade civil objetiva aplicada às pessoas jurídicas, em regra, não há necessidade de comprovação da culpa, ou seja, a responsabilidade será atribuída diretamente ao agente responsável, sem verificar se houve qualquer intenção ou não do sujeito que diretamente praticou o ato prejudicial: " [n]a responsabilidade civil objetiva prescinde-se totalmente da prova da culpa. Ela é reconhecida, como mencionado independentemente de culpa. Basta, assim, que haja relação de causalidade entre a ação e o dano". (GONÇALVES. 2018. p. 49).

Carolina Salles (2013) ao fazer uma análise do Ordenamento Jurídico Ambiental, afirma que o Direito Ambiental adotou a teoria objetiva da responsabilidade civil, enquanto que a espécie subjetiva é aquela que encontramos como regra, no Código Civil de 2002.

Porém, diferentemente da Lei Civil que admite a aplicação da responsabilidade civil subjetiva à pessoa física, sempre que esta agir com culpa ou dolo, o Direito Ambiental não admite exceções quanto à objetividade da responsabilidade:

Da mesma forma, o artigo $14 \S 1^{\circ}$ da Lei 6.938/81 (Lei da Política Nacional do Meio Ambiente) adotou a teoria objetiva da responsabilidade civil: "Sem obstar a aplicação das penalidades neste artigo, é o poluidor obrigado, independentemente da existência da culpa, a indenizar ou reparar os danos causados ao meio ambiente e a terceiros, afetados por sua atividade". (SALLES. 2013. p.03, grifo do autor).

Ademais, no artigo 225, § $3^{\circ}$ da Carta, há a previsão da aplicação da responsabilidade civil objetiva aos sujeitos que causam prejuízo ao meio ambiente, o mesmo dispositivo aplicado pela Lei Civil para as pessoas jurídicas. Vale ainda relembrar que o referido parágrafo vai além da esfera cível, atingindo também as esferas penal e administrativa, in verbis:

$\S 3^{\circ}$. As condutas e atividades consideradas lesivas ao meio ambiente sujeitarão os infratores, pessoas físicas ou jurídicas, a sanções penais e administrativas, independentemente da obrigação de reparar os danos causados". (BRASIL. Constituição Federal, 1988)

Considerando que se determinado agente poluidor provocar algum dano ao meio ambiente, poderá ele responder, simultaneamente, civil, administrativa e criminalmente, sem prejuízo uma da outra, ou seja, poderá responder cumulativamente pelo dano causado.

Cabe ressaltar que Tartuce (2018), em sua obra, traz alguns exemplos de quando a responsabilidade civil objetiva é aplicada e prevista em lei:

Em relação aos casos estabelecidos em lei, como primeiro exemplo, cite-se a responsabilidade objetiva dos fornecedores de produtos e prestadores de serviços frente aos consumidores, prevista no Código de Defesa do Consumidor (Lei 8.078/1990). Como segundo exemplo, destaque-se a responsabilidade civil ambiental, consagrada de Lei da Política Nacional do Meio Ambiente (art. 14, $\$ 1^{\circ}$ da Lei 6.938/1981. (TARTUCE. 2018. p. 507. Grifo nosso) 
Portanto, ao analisar vê-se que a Lei da Política Nacional do Meio Ambiente, mostra-se exata em seu artigo $14, \S 1^{\circ}$, ao adotar a responsabilidade civil objetiva como regra:

$\S 1^{\circ}$ - Sem obstar a aplicação das penalidades previstas neste artigo, é o poluidor obrigado, independentemente da existência de culpa, a indenizar ou reparar os danos causados ao meio ambiente e a terceiros, afetados por sua atividade. O Ministério Público da União e dos Estados terá legitimidade para propor ação de responsabilidade civil e criminal, por danos causados ao meio ambiente. (BRASIL. Planalto, Lei 6.938/1981)

Assim sendo, diferentemente do Código Civil, que adota como regra a responsabilidade subjetiva, o Direito Ambiental adota a responsabilidade civil objetiva, ou seja, não depende da apuração de eventual culpa ou dolo por parte do agente poluidor, de acordo com o artigo supramencionado.

Conforme já demonstrado, o direito ambiental adota a responsabilidade civil objetiva para a reparação dos danos e além de toda a sociedade, o Estado também tem o dever de proteger e preservar o meio ambiente.

Tendo em vista este dever do Estado, há casos em que o próprio poder público pratica atos danosos ao meio ambiente; em ocorrendo isto, uma vez comprovado, não há o que se discutir com relação à isenção da responsabilidade por parte da entidade pública.

Conforme Hugo Nigro Mazzilli (2018. p. 216), “[o] Estado também pode ser responsabilizado pela prática de danos ambientais [...]". Resta, então, sem sombra de dúvidas, que o Estado deve reparar os danos causados não só ao meio ambiente como um todo, mas, especificamente, ao cidadão exposto à poluição sonora provocada pelos meios de transporte público.

Podemos observar, no julgado a seguir colacionado, que o Distrito Federal foi condenado, a partir de uma ação civil pública ajuizada pelo Ministério Público do Trabalho, ao pagamento milionário de $\mathrm{R} \$ 10.000 .000,00$ (dez milhões de reais) a título de danos morais coletivos, pelo fato de não ter fiscalizado corretamente o seu sistema de transporte - no caso, os motoristas dos ônibus eram expostos diariamente à poluição sonora:

Na presente ação [...], o Ministério Público do Trabalho busca a condenação do ente público em indenização por dano moral coletivo, por ele não ter fiscalizado adequadamente o sistema de transporte, permitindo que a empresa prestasse serviços à população expondo seus empregados a riscos causados por ruídos excessivos no curso da atividade. (Tribunal Regional do Trabalho da $10^{a}$ Região. Recurso Ordinário, 015892012-011-10-00-4 RO, Relator: DESEMBARGADOR JOÃO AMÍLCAR, Órgão Julgador: $2^{\mathrm{a}}$ Turma, Data de Julgamento: 13/04/2016, Data da Publicação no Diário: 27/05/2016)

Ainda, o Tribunal Regional do Trabalho da $10^{a}$ Região reconheceu a omissão do Estado em adotar medidas necessárias para a prevenção, ou até mesmo para a 
supressão do problema, caso em que, a empresa contratada utilizava veículos que colocavam em risco a saúde dos motoristas, e justamente por ter sido contratada pelo poder público, a falta de fiscalização resultou na responsabilização objetiva:

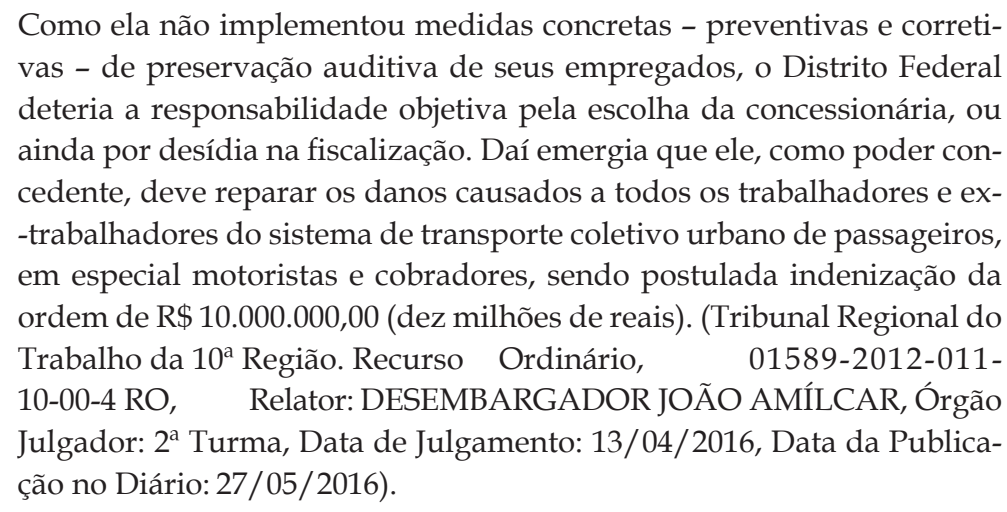

Outro caso semelhante ocorreu em São Paulo, onde, em ação por danos morais, o autor alegou sofrer grande incômodo pela passagem dos trens da Companhia Paulista de Trens Metropolitanos (CPTM) perto de sua residência, e, apesar do juízo reconhecer que a responsabilidade era da construtora do edifício, pois não se atentou aos fatores externos em seu entorno, reconheceu também que os ruídos emitidos pela linha de trem estavam acima do permitido, possibilitando eventuais danos à saúde dos condôminos:

Segundo o laudo pericial, os ruídos produzidos pelas passagens de trens e metrôs nas linhas da CPTM são mais elevados do que o permitido pelas Normas NBR 10.151/00 e NBR 10.152/87. Às folhas 307/308, encontram-se as tabelas elaboradas pelo perito, nas quais se definiu os níveis de ruídos comparados com os permitidos pelas normas supracitadas. A conclusão do perito de que os níveis de ruídos emitidos estão acima dos limites legais. (Tribunal de Justiça do Estado de São Paulo. Apelação Nº1036338- 93.2013.8.26.0100. Relator: Desembargador Fábio Henrique Podestá, Órgão Julgador: $5^{a}$ Câmara de Direito Privado, Data de Julgamento: 19/10/2015, Data da Publicação no Diário: 20/10/2015)

Diante desta situação, fica evidente que os ruídos emitidos pelo transporte público estão acima do permitido pela legislação, porém, no caso a seguir apreciado, o Tribunal de Justiça do Estado de São Paulo entendeu que era dever da construtora adequar a construção do edifício a fim de minimizar os ruídos do transporte público, e não da CPTM. Ademais, deixou claro que caberia à consumidora a verificação dessas condições negativas, antes da compra do imóvel:

Apesar da proximidade com as linhas de trens previamente conhecida pela consumidora/autora, motivo relevante na decisão da compra, era dever da construtora fornecer uma estrutura que se adequasse aos limites estabelecidos pelas normas. (Tribunal de Justiça do Estado de 
São Paulo. Apelação N¹036338-93.2013.8.26.0100. Relator: Desembargador Fábio Henrique Podestá, Órgão Julgador: $5^{\mathrm{a}}$ Câmara de Direito Privado, Data de Julgamento: 19/10/2015, Data da Publicação no Diário: 20/10/2015)

Por outro lado, no estado do Paraná, o Ministério Público Estadual ajuizou ação civil pública contra o município de Curitiba, juntamente com a empresa de transporte contratada, na qual respondeu por danos ambientais pela emissão de poluição sonora e atmosférica acima do permitido:

APELAÇÃO CÍVEL. AÇÃO CIVIL PÚBLICA DE RESPONSABILIDADE POR DANOS CAUSADOS AO MEIO AMBIENTE. POLUIÇÃO ATMOSFÉRICA E SONORA. EMPRESA RÉ QUE ATUA NO RAMO DE TRANSPORTE COLETIVO DE PASSAGEIROS DE ÔNIBUS. RECLAMAÇÃO DA COMUNIDADE QUE RESIDE NAS PROXIMIDADES DO PÁTIO DA EMPRESA, DESCONTENTES COM O DESLOCAMENTO DE POEIRA E O RUÍDO EXCESSIVO PROVOCADO PELO MOVIMENTO INTENSO E CONTÍNUO DOS ÔNIBUS DA EMPRESA, INCLUSIVE DURANTE O PERÍODO NOTURNO. MINISTÉRIO PÚBLICO QUE PRETENDE A RELOCAÇÃO DAS ATIVIDADES DA EMPRESA, POIS O LOCAL ONDE A MESMA SE ENCONTRA INSTALADA VIOLA A LEGISLAÇÃO MUNICIPAL DE ZONEAMENTO. PEDIDO DE INDENIZAÇÃO POR DANOS MATERIAIS E MORAIS, E DA ABSTENÇÃO DA PRÁTICA DA ATIVIDADE NAQUELE LOCAL. JUÍZA QUE JULGOU IMPROCEDENTES OS PEDIDOS. (Tribunal de Justiça do Estado do Paraná. Apelação no 381375-6. Relator: Desembargador Marcos de Luca Fanchin, Órgão Julgador: $4^{\text {a }}$ Câmara Cível, Data de Julgamento: 30/10/2007, Data da Publicação no Diário: 23/11/2007).

Assim, na mesma ação, o órgão municipal responsável pelos assuntos do meio ambiente comprovou em juízo o dano ambiental e, consequentemente, o descumprimento da legislação local sobre a emissão de ruídos:

2. POLUIÇÃO ATMOSFÉRICA E SONORA COMPROVADA. LAUDOS EMITIDOS PELA SECRETARIA MUNICIPAL DO MEIO AMBIENTE QUE DEMONSTRAM A POLUIÇÃO AMBIENTAL PROVOCADA PELAS ATIVIDADES DA EMPRESA REQUERIDA, POR MEIO DO DESLOCAMENTO DE POEIRA E RUÍDOS EXCESSIVOS PROVOCADOS PELA CONTÍNUA MOVIMENTAÇÃO DA FROTA DE ÔNIBUS. VIOLAÇÃO DA LEI MUNICIPAL No 10.625/2002 QUE ESTABELECE OS LIMITES PARA A PRODUÇÃO DE RUÍDOS DE ACORDO COM A ZONA EM QUE SE LOCALIZA O IMÓVEL. EMPRESA REQUERIDA QUE ULTRAPASSOU OS LIMITES ESTABELECIDOS NA LEGISLAÇÃO E SE COMPROMETEU A RELOCAR SUAS ATIVIDADES PARA A CIDADE INDUSTRIAL, ONDE ADQUIRIU TERRENO. CRONOGRAMA DE RELOCAÇÃO QUE NÃO FOI CUMPRIDO. RECURSO PROVIDO NESTE ASPECTO. (Tribunal de Justiça do Estado do Paraná. Apelação no 381375-6. Relator: Desembargador Marcos de Luca Fanchin, Órgão Julgador: $4^{\text {a }}$ Câmara Cível, Data de Julgamento: 30/10/2007, Data da Publicação no Diário: 23/11/2007) 
Portanto, visto as ações colacionadas, observa-se que o estado vem compondo o polo passivo juntamente com a empresa contratada e, neste sentido, o ente público também responde de forma solidária, ou por não realizar a devida fiscalização, ou por não observar e obedecer os limites de incomodidade estabelecidos em lei.

O Ministério Público é Instituição essencial na defesa da sociedade, tão importante que a Constituição Federal, em seu artigo 127, determina a sua existência em caráter permanente.

Como uma de suas diversas funções, a Constituição atribui ao Ministério Público, em seu artigo 129, inciso III, a proteção ao Meio Ambiente, a partir de seus mecanismos de atuação:

Art. 129. São funções institucionais do Ministério Público:

...

- promover o inquérito civil e a ação civil pública, para a proteção do patrimônio público e social, do meio ambiente e de outros interesses difusos e coletivos; (BRASIL. Constituição da República Federativa do Brasil, 1988)

Por outro lado, e em conformidade com a Constituição Federal, a Lei Orgânica Nacional do Ministério Público (Lei No 8.625/1993) dispõe em seu artigo 25, inciso IV e alínea "a", a promoção de inquérito civil e ação civil pública visando a tutela do meio ambiente. $O$ texto legal vai além, entendendo que esses mecanismos servem, também, para a prevenção e reparação dos danos ao meio ambiente:

Art. 25. Além das funções previstas nas Constituições Federal e Estadual, na Lei Orgânica e em outras leis, incumbe, ainda, ao Ministério Público:

$\ldots$

- promover o inquérito civil e a ação civil pública, na forma da lei:

a) para a proteção, prevenção e reparação dos danos causados ao meio ambiente, ao consumidor, aos bens e direitos de valor artístico, estético, histórico, turístico e paisagístico, e a outros interesses difusos, coletivos e individuais indisponíveis e homogêneos. (BRASIL. Planalto, Lei 8.625/1993).

Deste modo, evidente que o Ministério Público deve agir e atuar em defesa do meio ambiente. Em seguida, abordaremos os mecanismos que esta instituição poderá utilizar-se para a proteção, prevenção e reparação dos danos ambientais.

$\mathrm{O}$ inquérito civil é um procedimento administrativo interno utilizado pelo Ministério Público e, segundo Mazzilli, possui o objetivo básico de "colher elementos de convicção para eventual propositura de ação civil pública [...]". (MAZZILLI. 2017. p. 549).

Assim, o artigo $2^{\circ}$ do Ato Normativo $\mathrm{N}^{\circ} 484$ - CPJ - do Ministério Público de São Paulo, define o inquérito civil como uma investigação de caráter inquisitorial, unilateral e facultativo: 
Art. $2^{\circ} \mathrm{O}$ inquérito civil é investigação administrativa de caráter inquisitorial, unilateral e facultativo, instaurado e presidido pelo Ministério Público e destinado a apurar ocorrência de danos efetivos ou potenciais a direitos ou interesses difusos, coletivos ou individuais homogêneos ou outras que lhe incuba defender, servindo como preparação para o exercício das atribuições inerentes às suas funções institucionais. (SÃO PAULO. Ministério Público do Estado de São Paulo, Ato Normativo 484-CPJ/2006).

Vale ainda ressaltar que a instauração do inquérito civil não é obrigatória, uma vez que, se o Ministério Público entender possuir provas suficientes, poderá propor, diretamente, a ação civil pública, conforme o parágrafo único do artigo $2^{\circ}$ do mesmo Ato Normativo.

Parágrafo único. O inquérito civil não é condição de procedibilidade para o ajuizamento das ações a cargo do Ministério Público, nem para a concretização das demais medidas de sua competência própria. (SÃO PAULO. Ministério Público do Estado de São Paulo, Ato Normativo 484- CPJ/2006)

Por fim, não existindo causas de indeferimento, o inquérito civil poderá tomar dois rumos: a propositura de ação civil pública ou a promoção de seu arquivamento, por não haver motivos suficientes para o ingresso da ação, conforme o artigo 90 do Ato Normativo $N^{\circ} 484$ :

Art. 90. O inquérito civil será encerrado, depois de esgotadas todas as diligências a que se destinava, mediante:

- propositura de ação civil pública;

- arquivamento. (SÃO PAULO. Ministério Público do Estado de São Paulo, Ato Normativo 484-CPJ/2006)

Passada a fase inquisitorial, ou tendo provas suficientes, o Ministério Público, representado pelo seu promotor de justiça ou procurador de justiça, ajuizará ação civil pública, para que determinado poluidor repare todos os danos causados ao meio ambiente e à coletividade.

Em conceito simples, a ação civil pública, segundo Mazzilli (2017. p. 77), "é a ação de objeto não penal proposta pelo Ministério Público".

Mazzilli (2017) ainda entende que, apesar da ação coletiva e ação civil pública serem a mesma coisa, o mais correto ao Ministério Público é denominar de ação civil pública.

Quanto aos demais legitimados, como as associações civis, o certo é denominar de ação coletiva:

Se ela estiver sendo movida pelo Ministério Público, o mais correto, sob o prisma doutrinário, será chamá-la de ação civil pública. Mas se tiver sido proposta por associações civis, mais correto será denominá-la ação coletiva. [...] De qualquer forma, porém, nenhuma ação de objeto coletivo poderá ser rejeitada apenas porque o autor a chamou de coletiva em vez civil pública, ou vice-versa... A mera nomenclatura será irrelevante. (MAZZILLI. 2017. p.78). 
A Lei nº 7.347 de 24 de julho de 1985, dispõe sobre a ação civil pública, demonstrando, no primeiro artigo, seu cabimento para os danos ambientais, sejam eles difusos, coletivos ou individuais homogêneos, conforme estabelecido, também, na "Súmula 601, STJ: O Ministério Público tem legitimidade ativa para atuar na defesa de direitos difusos, coletivos e individuais homogêneos dos consumidores, ainda que decorrentes da prestação de serviço público".

\footnotetext{
Regem-se pelas disposições desta Lei, sem prejuízo de ação popular, as ações de responsabilidade por danos morais e patrimoniais causados:

I - Ao meio ambiente;

IV - a qualquer outro interesse difuso ou coletivo. (BRASIL. PLANAL-

TO. Lei $\left.n^{\circ} 7.347 / 1985\right)$
}

Assim, conforme demonstrado no capítulo anterior, o Ministério Público atuou de forma presente nas causas que envolviam o meio ambiente e sua poluição, tal é o fato que, conforme a jurisprudência apresentada, houve o ajuizamento de ações, nas quais restou comprovada a falta de fiscalização e a inobservância de preceitos legais, por parte da administração pública.

Desse modo, o Ministério Público possui um papel fundamental na defesa do meio ambiente, sendo uma instituição cuja finalidade é proteger e preservar a natureza, o bem-estar e toda a sociedade.

\section{CONSIDERAÇÕES FINAIS}

Diante da realidade urbana vivida em nosso dia a dia, com tantas questões que afetam negativamente a população, a poluição é um dos principais problemas ambientais na Região Metropolitana de São Paulo, especialmente quanto ao que se refere à emissão de ruídos provocados pelo transporte público.

Com o rápido e constante crescimento e desenvolvimento da Região Metropolitana de São Paulo, objeto de nossa análise, a necessidade do transporte fez com que a poluição sonora se agravasse, exigindo a criação de leis que estabelecessem parâmetros de incomodidade mínima.

Há de se ressaltar que a própria Constituição Federal prevê, em seu artigo 23 , a proteção do meio ambiente, com relação ao controle e combate de todas as formas de poluição, por parte dos entes federativos (União, estados, municípios e o Distrito Federal). Juntamente com o artigo 225, o equilíbrio do meio ambiente no sentido lato é considerado como um direito fundamental de todo brasileiro, incumbindo a todos os entes federativos, somados à sociedade e a cada um de nós, a tutela adequada e manutenção de sua sanidade.

É certo que já existem leis neste sentido, porém, são dispersas e variáveis, de acordo com cada município, não existindo uma legislação específica, de cunho nacional, que trate exclusivamente sobre a poluição sonora sentida nas metrópoles.

Conforme pode ser apreciado em nossa pesquisa, o que temos em relação ao nosso tema são somente alguns projetos de lei, que nos parecem estagnados, sem 
qualquer espécie de motivação que lhes dê impulso ou que os possibilite seguir em frente, transformando-se em lei efetiva, com relação aos ruídos provocados pelo transporte público, assim como sua perniciosidade, nos grandes centros urbanos.

O próprio Senado Federal, podemos constatar, reconheceu a falta de legislação específica, o que resulta em grande insegurança jurídica com relação a este tema.

Em São Paulo, apesar de haver previsão da criação de uma lei sobre os ruídos emitidos por veículos, o fato é que até o momento esta não existe, efetivamente, mas apenas normas dispondo quanto aos veículos próprios da administração pública municipal, não estendendo seus efeitos aos utilizados pelo transporte público coletivo.

Já o município de Santo André possui legislação tratando exclusivamente da emissão de ruídos por quaisquer veículos. Por analogia, ao interpretar a lei, os veículos utilizados pelo transporte público coletivo também estão sujeitos a essa legislação.

Finalmente, no município de São Bernardo do Campo, também há regulamento sobre a emissão de ruídos, que se mostrou de forma unificada, pois não trata somente dos veículos automotores, mas abrange a quaisquer formas de emissão dos ruídos.

Concluindo, as legislações analisadas e aquelas que ainda serão legisladas servem não somente para a proteção e preservação do meio ambiente, mas, também, para garantir a saúde e o bem estar de toda a população, inclusive de todos os seres vivos inseridos no ambiente.

Há de mencionar que tanto a Região Metropolitana de São Paulo, quanto o próprio Brasil, carecem de estudos aprofundados sobre os ruídos, como por exemplo, o demonstrado na Europa, que já possui pesquisas e recomendações, comprovando que a população regional está exposta a níveis elevados de ruídos decorrente da poluição sonora.

O respeito às normas ambientais federais deve ser somado às regras estaduais e municipais no sentido de se garantir um meio ambiente ecologicamente equilibrado para uso da atual e das futuras gerações, conforme nos informa a Constituição Federal de 1988.

Não podemos nos esquecer de um fato: o ser humano, assim como todas as espécies não humanas dispõem apenas de uma casa, o planeta Terra. De sua proteção e saúde depende a nossa sobrevivência digna. Incumbe, a cada um de nós, o exercício da consciência ecológica.

É dever de cada um dos países a preservação adequada e a devida informação, aos seus cidadãos, sobre a importância de se manter a saúde do planeta, já que uma casa doente não traz vivência saudável aos seus habitantes.

\section{REFERENNCIAS}

AGÊNCIA SENADO. Poluição sonora prejudica a saúde e preocupa especialistas. 2018. Disponível em: <https://www12.senado.leg.br/noticias/especiais/especial-cidadania/ poluicao- sonora-prejudica-a-saude-e-preocupa-especialistas/poluicao-sonora-prejudica-a-saude-e- preocupa-especialistas>. Acesso em: 11 nov. 2019. 
BOM Dia Brasil - Edição de quarta-feira, 24/04/2019. São Paulo: Globo, 2019. (60 min.), son., color. Disponível em: <https://globoplay.globo.com/v/7563896/>. Acesso em: 24 abr. 2019.

BRASIL. CAMARA DOS DEPUTADOS. Projeto de Lei n ${ }^{\circ} 1.073$, de 2015. Acrescenta o $\S 4^{\circ}$ ao art. 54 da Lei n ${ }^{0}$ 9.605, de 12 de dezembro de 1998 - Lei de Crimes Ambientais - para dispor sobre o crime de poluição sonora. Disponível em:

<https:/ / www.camara.leg.br/proposicoesWeb/fichadetramitacao?idProposicao=1199017>. Acesso em: 28 ago. 2019.

BRASIL. Constituição (1988). Constituição da República Federativa do Brasil: promulgada em 5 de outubro de 1988. Disponível em:

<http://www.planalto.gov.br/ccivil_03/constituicao/constituicao.htm>. Acesso em: 03 set. 2019.

BRASIL. Lei Complementar $\mathbf{n}^{\mathbf{0}}$ 14, de 08 de junho de 1973. Estabelece as regiões metropolitanas de São Paulo, Belo Horizonte, Porto Alegre, Recife, Salvador, Curitiba, Belém e Fortaleza. Brasília. Disponível em:

<http://www.planalto.gov.br/ccivil_03/leis/lcp/Lcp14.htm>. Acesso em: 05 nov. 2019.

BRASIL. Lei $\mathbf{n}^{\mathbf{0}} \mathbf{1 0 . 2 5 7}$, de 10 de julho de 2001. Regulamenta os arts. 182 e 183 da Constituição Federal, estabelece diretrizes gerais da política urbana e dá outras providências. Estatuto da Cidade. Disponível em: <http://www.planalto.gov.br/ccivil_03/leis/leis_2001/ 110257.htm>. Acesso em: 08 set. 2019.

BRASIL. Lei $\mathbf{n}^{\mathbf{0}}$ 10.406, de 10 de janeiro de 2002. Institui o Código Civil. Brasília, Disponível em: <http://www.planalto.gov.br/ccivil_03/leis/2002/110406.htm>. Acesso em: 30 set. 2019.

BRASIL. Lei $\mathbf{n}^{\mathbf{0}}$ 12.587, de 03 de janeiro de 2012. Vigência Institui as diretrizes da Política Nacional de Mobilidade Urbana; revoga dispositivos dos Decretos-Leis n's 3.326, de 3 de junho de 1941, e 5.405, de 13 de abril de 1943, da Consolidação das Leis do Trabalho (CLT), aprovada pelo Decreto-Lei $n^{\circ} 5.452$, de $1^{\circ}$ de maio de 1943, e das Leis $n^{\circ} \mathrm{s} 5.917$, de 10 de setembro de 1973, e 6.261, de 14 de novembro de 1975; e dá outras providências. Política Nacional de Mobilidade Urbana. Disponível em:

<http://www.planalto.gov.br/ccivil_03/_ato2011-2014/2012/lei/112587.htm>. Acesso em: 05 nov. 2019.

BRASIL. Lei $\mathbf{n}^{\mathbf{0}} \mathbf{1 3 . 0 8 9}$, de 12 de janeiro de 2015. Institui o Estatuto da Metrópole, altera a Lei $n^{\circ} 10.257$, de 10 de julho de 2001, e dá outras providências. Estatuto da Metrópole.

Disponível em: <http://www.planalto.gov.br/ccivil_03/_ato2015-2018/2015/lei/113089. htm>. Acesso em: 31 out. 2019.

BRASIL. Lei $\mathbf{n}^{\mathbf{0}}$ 6.938, de 31 de agosto de 1981. Dispõe sobre a Política Nacional do Meio Ambiente, seus fins e mecanismos de formulação e aplicação, e dá outras providências. 
Disponível em: <http://www.planalto.gov.br/ccivil_03/Leis/L6938.htm>. Acesso em: 25 ago. 2019.

BRASIL. Lei $\mathbf{n}^{\text {0 }}$ 7.347, de 24 de julho de 1985. Disciplina a ação civil pública de responsabilidade por danos causados ao meio-ambiente, ao consumidor, a bens e direitos de valor artístico, estético, histórico, turístico e paisagístico (VETADO) e dá outras providências. Brasília, Disponível em: <http://www.planalto.gov.br/ccivil_03/leis/17347orig.htm>. Acesso em: 14 nov. 2019.

BRASIL. Lei $\mathbf{n}^{\mathbf{0}} \mathbf{8 . 6 2 5}$, de 12 de fevereiro de 1993. Institui a Lei Orgânica Nacional do Ministério Público, dispõe sobre normas gerais para a organização do Ministério Público dos Estados e dá outras providências. Brasília, Disponível em: <http:/ / www.planalto.gov.br/ ccivil_03/Leis/L8625.htm>. Acesso em: 13 nov. 2019.

DISTRITO FEDERAL E TOCANTINS. Tribunal Regional do Trabalho da $10^{a}$ Região. Acordão no TRT 0001589-73.2012.5.10.0011 RO. Ministério Público do Trabalho. Distrito Federal e Rapido Brasilia Transportes e Turismo Ltda. Relator: Desembargador João Amílcar. Brasília, 13 de abril de 2016. Recurso Ordinário Nº 01589-2012-011-10-00-4 Ro. [distrito Federal], 27 maio 2016. Disponível em: <http:/ /www.trt10.jus.br/consweb_gsa/ gsa_segunda_instancia.php?tip_processo_trt=RO\&ano_processo_trt=2013\&num_processo_trt $=10347 \&$ num_processo_voto $=413248 \& d$ ta_publicaca o $=27 / 05 / 2016 \& d t a \_j u l g a m e n-$ to=13/04/2016\&embargo=\&tipo_publicacao=DEJT\&termos=>. Acesso em: 14 nov. 2019.

FIORILLO, Celso Antonio Pacheco. Curso de Direito Ambiental Brasileiro. 14. ed. São Paulo: Saraiva, 2013.

GONÇALVES, Carlos Roberto. Direito Civil Brasileiro: Responsabilidade Civil. 13. ed. São Paulo: Saraiva, 2018. 4 v.

IBGE. Censo Demográfico 2010: População do município de Santo André - SP no último censo. 2010. Disponível em: https://cidades.ibge.gov.br/brasil/sp/santo-andre/panorama. Acesso em: 12 jun. 2020.

IBGE. Censo Demográfico 2010: População do município de São Bernardo do Campo - SP no último censo. 2010. Disponível em: https:/ / cidades.ibge.gov.br/brasil/sp/sao-bernardo-do- campo/panorama. Acesso em: 12 jun. 2020.

IBGE. Estimativas da população residente com data de referência $1^{\circ}$ de julho de 2019 : População estimada no município de São Paulo - SP. 2019. Disponível em: https:/ / cidades. ibge.gov.br/brasil/sp/sao-paulo/panorama. Acesso em: 12 jun. 2020.

MATURANA. A poluição que ninguém vê avança contra a saúde, Jornal do Senado, 2012, p. 01 
MAZZILLI, Hugo Nigro. A Defesa dos Interesses Difusos em Juízo. 30. ed. São Paulo: Saraiva, 2017.

PARANÁ. Tribunal de Justiça do Estado do Paraná. Acordão no 381375-6. MINISTÉRIO PÚBLICO DO ESTADO DO PARANÁ. AUTO VIAÇÃO REDENTOR LTDA E

MUNICÍPIO DE CURITIBA. Relator: Desembargador Marcos de Luca Fanchin. Curitiba, 30 de outubro de 2007. Apelação cível. Curitiba, 23 nov. 2007. Disponível em:

<https://portal.tjpr.jus.br/jurisprudencia/j/1620675/Acórdão-381375-6>. Acesso em: 14 abr. 2019.

PATRIOTA, Gonzaga. A importância do transporte público de qualidade. 2013. Disponível em: <http:/ / www.psbnacamara.org.br/art_det.asp?det=172>. Acesso em: 05 nov. 2019.

SALLES, Carolina. A responsabilidade civil no direito ambiental. 2013. Disponível em:

<https:/ / carollinasalle.jusbrasil.com.br/artigos/112179580/a-responsabilidade-civil-no-direito- ambiental>. Acesso em: 04 set. 2019.

SANTO ANDRÉ. Lei $\mathbf{n}^{\mathbf{0}} \mathbf{9 . 6 0 8}$, de 21 de julho de 2014. Dispõe sobre a limitação quanto à emissão de sons e ruídos provenientes de veículos de todas as espécies. Disponível em:

<https:/ / consulta.siscam.com.br/camarasantoandre/Documentos/Documento/40957>. Acesso em: 26 out. 2019.

SÃO BERNARDO DO CAMPO. Lei $\mathbf{n}^{\mathbf{0}} \mathbf{6 . 3 2 3}$, de 19 de dezembro de 2013. Dispõe sobre o controle de ruídos ou sons por veículos automotores, estabelece níveis, padrões de emissão em zonas de restrição de ruído, e dá outras providências. Disponível em: <https:/ / leismunicipais.com.br/a2/sp/s/sao-bernardo-do-campo/lei-ordinaria/2013/633/6323/ lei-ordinaria-n-6323-2013-dispoe-sobre-o-controle-de-ruidos-ou-sons-por-veiculos-automotores-estabelece-niveis-padroes-de-emissao-em-zonas-de-restricaode-ruido-e-da-outras-providencias?q=ru\% C3\%ADdos>. Acesso em: 28 out. 2019.

SÃO PAULO (Estado). Ato Normativo no 484, de 05 de outubro de 2006. Disciplina o inquérito civil e demais investigações do Ministério Público na área dos interesses difusos, coletivos e individuais homogêneos, as audiências públicas, os compromissos de ajustamento de conduta e as recomendações, e dá outras providências. São Paulo, Disponível em: <http:/ / biblioteca.mpsp.mp.br/PHL_img/ATOS/484.pdf>. Acesso em: 14 nov. 2019.

SÃO PAULO (Estado). Lei Complementar $\mathbf{n}^{\mathbf{0}} \mathbf{1 . 1 3 9}$, de 16 de junho de 2011. Reorganiza a Região Metropolitana da Grande São Paulo, cria o respectivo Conselho de Desenvolvimento e dá providências correlatas. São Paulo, Disponível em: <https:/ /www.al.sp.gov.br/ repositorio/legislacao/lei.complementar/2011/lei.complementar- 1139-16.06.2011.html>. Acesso em: 20 out. 2019. 
SÃO PAULO (Município). Lei $\mathbf{n}^{\mathbf{0}} \mathbf{1 6 . 4 0 2}$, de 22 de março de 2016. Disciplina o parcelamento, o uso e a ocupação do solo no Município de São Paulo, de acordo com a Lei $n^{\circ} 16.050$, de 31 de julho de 2014 - Plano Diretor Estratégico (PDE). Disponível em:

<http:/ / legislacao.prefeitura.sp.gov.br/leis/lei-16402-de-22-de-marco-de-2016>. Acesso em: 24 ago. 2019.

\section{SÃO PAULO. EMPRESA PAULISTA DE PLANEJAMENTO METROPOLITANO. Região}

Metropolitana de São Paulo: Sobre a RMSP. 2019. Disponível em: <https:/ emplasa.sp. gov.br/RMSP>. Acesso em: 31 out. 2019.

SÃO PAULO. Tribunal de Justiça do Estado de São Paulo. Acordão n ${ }^{\circ} 10279$. ATUA CONSTRUTORA E INCORPORADORA S/A. RAFAELA SANTANA DE SOUSA. Relator: Desembargador Fábio Henrique Podestá. São Paulo, 19 de outubro de 2015. Apelação No 1036338-93.2013.8.26.0100. São Paulo, 20 out. 2015. Disponível em: <https://esaj.tjsp.jus. $\mathrm{br} / \mathrm{cjsg}$ / getArquivo.do?cdAcordao=8907276\&cdForo=0>. Acesso em: 14 abr. 2019.

SENADO FEDERAL. A poluição que ninguém vê avança contra a saúde. Jornal do Senado. Brasília, p. 1-1. 19 jun. 2012. Disponível em: <https:/ / www2.senado.leg.br/bdsf/ bitstream/handle/id/242653/120619_393.pdf?sequence=1>. Acesso em: 11 nov. 2019.

TARTUCE, Flávio. Direito Civil: Direito das Obrigações e Responsabilidade Civil. 13. ed. Rio de Janeiro: Forense, 2018. 2 v.

WORLD HEALTH ORGANIZATION. Data and statistics. 2011. Disponível em: <http:/ / www.euro.who.int/en/health-topics/environment-and-health/noise/data-and-statistics>. Acesso em: 25 nov. 2019.

WORLD HEALTH ORGANIZATION. Environmental Noise Guidelines for the European Region. Copenhagen: Regional Office For Europe, 2018. Disponível em: <https:/ / apps. who.int/iris/handle/10665/279952>. Acesso em: 06 nov. 2019.

WORLD HEALTH ORGANIZATION. Noise. 2019. Disponível em: <http:/ /www.euro. who.int/en/health-topics/environment-and-health/noise>. Acesso em: 25 nov. 2019. 